\title{
The mandible and its foramen: anatomy, anthropology, embryology and resulting clinical implications
}

\author{
M. Lipski1*, I.M. Tomaszewska2* , W. Lipska³ ${ }^{3}$, G.J. Lis ${ }^{4}$, K.A. Tomaszewski ${ }^{1}$ \\ ${ }^{1}$ Department of Anatomy, Jagiellonian University Medical College, Krakow, Poland \\ 2Department of Medical Didactics, Jagiellonian University Medical College, Krakow, Poland \\ ${ }^{3}$ Department of Periodontology and Oral Medicine, Institute of Dentistry, Jagiellonian University Medical College, \\ Krakow, Poland \\ ${ }^{4}$ Department of Histology, Jagiellonian University Medical College, Krakow, Poland
}

[Received 21 April 2013; Accepted 21 May 2013]

*These Authors contributed equally to this work.

\begin{abstract}
The aim of this paper is to summarise the knowledge about the anatomy, embryology and anthropology of the mandible and the mandibular foramen and also to highlight the most important clinical implications of the current studies regarding anaesthesia performed in the region of the mandible. An electronic journal search was undertaken to identify all the relevant studies published in English. The search included MEDLINE and EMBASE databases and years from 1950 to 2012. The subject search used a combination of controlled vocabulary and free text based on the search strategy for MEDLINE using key words: 'mandible', 'mandibular', 'foramen', 'anatomy', 'embryology', 'anthropology', and 'mental'. The reference lists of all the relevant studies and existing reviews were screened for additional relevant publications. Basing on relevant manuscripts, this short review about the anatomy, embryology and anthropology of the mandible and the mandibular foramen was written. (Folia Morphol 2013; 71, 4: 285-292)
\end{abstract}

Key words: mandible, human anatomy, inferior alveolar nerve block, mandibular foramen, mental protuberance

\section{INTRODUCTION}

The aim of this paper is to summarise the knowledge about the anatomy, embryology and anthropology of the mandible and the mandibular foramen, and also to highlight the most important clinical implications of the current studies regarding anaesthesia performed in the region of the mandible.

\section{METHODS}

An electronic journal search was undertaken to identify all the relevant studies published in English. This search included MEDLINE and EMBASE databases and years from 1950 to 2012. The subject search used a combination of controlled vocabulary and free text based on the search strategy for MEDLINE using the key words: 'mandible', 'mandibular', 'foramen', 'anatomy', 'embryology', 'anthropology', and 'mental'. The reference lists of all the relevant studies and existing reviews were screened for additional relevant publications.

Each publication was initially assessed for relevance using data presented in the abstract. When the abstract was not available or failed to provide sufficient information, a reprint of the full paper was obtained. When the papers or abstracts reported different stages of clinical trial, only the longer-term study was included in the review. When both the full paper and the abstract were published based on data from the same clinical trial, only the full paper was included. 


\section{ANATOMY OF THE MANDIBLE}

The mandible consists of flat bones. The corpus of the mandible is thicker than the rami. The points of maximum thickness are located on the level of the oblique line and the mandible-hyoid line. These are the places of maximum stress, which occurs when the mandible is pressed against the jaw [8]. The build of the compact bone is extremely dense, and the external and internal lamina are especially thick on the base of the mandible. The shape and character of the mandible is also fashioned by muscles and ligaments, that attach to this bone $[8,16,50,61]$. The internal sides (lingual) of the alveoli are much thicker than the external ones (buccal and labial), with the exception of the third molar, where the buccal side is the thickest $[8,28]$.

The ramus of the mandible has the shape of a quadrangular bone lamina. It has 2 surfaces and 2 condyles. The lateral surfaces are rough in the lower part. Near the angle of the mandible one can find the masseteric tuberosity, which is the place of attachment of the masseter muscle $[4,8,50,63]$. The medial side of the ramus holds the mandibular, and sometimes, accessory foramina $[2,8,43,48]$. The mandibular foramen is limited from the anterior side by a bony plate called the lingula of the mandible. The lingula is the place of attachment for the sphenomandibular ligament $[3,10]$. The lingula can be palpated through the mucosa of the oral cavity. It shows the way, where one should point the needle, when anaesthetising the nerve innervating the lower teeth [9, 29].

The mandibular canal begins with the mandibular foramen. This canal, when single, runs arching anteriorly, through the trabecular bone, to the level of the alveolus of the medial incisor. Near the mental foramen, the canal is wide, and narrows towards the medial side $[18,19]$. Near the mandibular foramen, or in the foramen itself, the mylohyoideus sulcus begins [10, 41, 58]. Going posteriorly from this sulcus, the medial surface of the mandible ramus is uneven, and forms the pterygoid tuberosity, where the medial pterygoid muscle attaches $[4,10]$. The medial side of this muscle is covered by the interpterygoid fascia [4, 31]. To the angle of the mandible, between the medial pterygoid muscle and the masseter muscle, the stylomandible ligament attaches.

The anterior edge of the mandible ramus begins as an extension of the oblique line. It is sharp and narrow, and medially borders the extramolar sulcus (at the buccal edge of the third molar). Medially from that border one can find the retromolar triangle, which lies posteriorly to the last molar. The medial border of this triangle is formed by the crist buccinatoria, which is the point at which the buccal muscle attaches. The lateral border of the retromolar triangle is created by the lateral branch of the crista temporalis $[4,31,56]$.

The posterior edge of the mandible is wide, round and covered by the parotid gland. The thin upper edge of the ramus has 2 condyles - the anterior coronoid process and the posterior condyloid process. These 2 are separated by the mandibular notch (incisura mandibulae) $[4,20,25]$.

\section{EMBRYOLOGY OF THE MANDIBLE}

The mandible begins to ossify as the second bone, after the clavicle $[8,16]$. The majority of the mandible forms as ossified connective tissue, on the lateral surface of the Meckel's cartilage. In each half of the mandible, an ossification centre develops [8]. It appears in the $6-7^{\text {th }}$ week of intrauterine development, and is the basis for the development of the main part of the mandibular corpus and rami. Next, clusters of cartilage begin to form in the connective tissue, which slowly starts to ossify irrespectively from Meckel's cartilage [8, 16, 28, $46,52]$. Such cartilage clusters form on the top of the coronoid and condyloid processes, in the angle of the mandible, on the anterior ends of both halves of the mandible and in the dental arch [8]. In the next step, all of these form a unified bone. Short before birth, in the connective tissue between both halves of the mandible, form 1 or 2 small mental bones (ossicula mentalia). These fuse with the mandible soon after birth [16] and create the mental protuberance. In the neonatal period, the mandible is formed from 2 halves, connected by the mandibular symphysis, which in humans and Primates ossifies in the first year after birth $[8,50,53,57]$.

The posterior end of the Meckel's cartilage connects to the area near the ear. The anterior ends of the left and right side of the cartilage almost contact with each other. The ossifying posterior end creates 2 auditory ossicles - the malleus and the incus. The anterior end is fused with the mandible, and the rest undergoes atrophy. The mylohyoid sulcus is the remnant of the groove, where the Meckel's cartilage existed. The sphenomandibular ligament develops from the fibrous sheath framing the cartilage $[8,28,46,50]$.

\section{DEVELOPMENT AND AGE-RELATED MANDIBULAR CHANGES}

After birth, the shape of the mandible is constantly modified. In neonates, the corpus of the mandible bilaterally holds the alveoli for both deciduous incisors, the 
canine tooth and 2 molars - not yet completely separated from each other [8]. In this period the mandibular canal is relatively wide, because it holds the yet divided inferior alveolar nerve and vessels. It is placed near the lower edge of the mandibular corpus. This form of separate innervation of the canine tooth, premolar and molar areas exists only in the neonatal period. In the persistent form, this canal exists posteriorly to the mandibular foramen, as the canal of Serres, which holds the Serres vein $[11,54]$.

The mental foramen is located low and relatively far towards the posterior, below the first molar bud [11, 22]. The angle between the corpus and the ramus of the mandible is obtuse $\left(150^{\circ}-160^{\circ}\right)$, and the condyloid process is small. However, the coronoid process in the mandible of a neonate is large and is located above the condyloid process $[8,28,38]$.

After birth both halves of the jaw fuse. This process takes place in the mandibular symphysis, and moves from the bottom to the top. Because of the developing buds of permanent teeth, the corpus elongates posteriorly from the mental foramen [28]. Together with the development of the alveolar part, the mandibular corpus height increases to make space for the elongating teeth roots.

When the permanent teeth start to erupt, the mandibular canal is located just above the mylohyoid sulcus, and the mental foramen moves anteriorly, reaching its final place on the level of the second premolar tooth $[8,18,19]$. The mandibular angle is less obtuse, and at the age of 4 has about $140^{\circ}[28,50]$.

When considering adults, the mandibular proportions are different, and the alveolar part of the mandible, as well as the base of the mandible are of similar height. The mandibular foramen moves cranially and positions itself in the centre of the corpus $[18,19$, 25]. The mandibular canal runs almost parallel to the mylohyoid line [31, 32, 37]. The angle between the corpus and the ramus becomes more perpendicular, between $120^{\circ}$ and $130^{\circ}[35,38,42,43]$.

In senile age, due to the loss of teeth, the size of the mandible decreases [38]. The alveolar part undergoes atrophy. Due to those changes, the main part of the corpus is localised below the oblique line, and the mandibular canal together with the mental foramen relatively move upwards, running near the dental arch. The mandibular ramus leans posteriorly, thus the mandibular angle increases, and once again is about $140^{\circ}$. The neck of the condyloid process leans posteriorly $[25,39,50]$.

\section{MANDIBLE INNERVATION}

Developmentally, both mandibular condyles are innervated by the third ramus of the trigeminal nerve the mandibular nerve [8]. This nerve is the "strongest" of the trigeminal branches and has a mixed character. Its lower branch holds the sensory function, and the upper one the motor function [61]. Pseudounipolar neurons that send axons to the mandibular nerve are located in the posterolateral part of the trigeminal ganglion. Those are mainly dendrites receiving fibres from the periodontium receptors. Taking into account the intracranial course, these 2 branches do not mix with each other. Fibre exchange occurs most probably at the level of and just below the oval foramen [6, 27, $60]$. At the start, the motor branch lies medially to the sensory one, next moves anteriorly, and lastly laterally.

The mandibular nerve innervates the mandible, the tempo-mandibular joint, the muscles, skin, mucosa, the periosteum, and all of the mandibular teeth. It exits the cranium through the oval foramen and goes posteriorly behind the lateral pterygoid muscle to the subtemporal fossa $[4,27,51,61]$. The mandibular nerve gives off:

- the anterior group — branches, which hold mainly the motor fibres;

- the posterior group — branches which hold mainly the sensory fibres.

The posterior group usually has 3 sensory branches - the lingual nerve, the inferior alveolar nerve and the auricotemporal nerve. The only sensory branch of the anterior group is the buccal nerve. It runs through the upper part of the subtemporal fossa and crosses the anterior edge of the mandibular ramus on the level of the upper molars (when the mouth is wide open) [38].

The inferior alveolar nerve is the only nerve from the posterior group that runs in the ossified mandibular canal. It branches off the posterior trunk, laterally from the lingual nerve, and runs between the medial and lateral pterygoid muscles [27]. Next it goes caudally and anteriorly between the sphenomandibular ligament and the mandibular ramus, towards the mandibular foramen. In the mentioned foramen, the nerve lies anteriorly and medially to the inferior alveolar artery. Such configuration occurs in $60 \%$ of the cases. In $20 \%$ the nerve is located laterally, and in $10 \%$ posteriorly to the artery. In $10 \%$ the nerve is placed independently to the artery [51]. Next, in the mandibular canal, the nerve is placed under the inferior alveolar vein. The inferior alveolar artery runs more cranially $[4,51]$. 
The inferior alveolar nerve has both the sensory and motor components. Before entering the mandibular canal it gives off the mylohyoid nerve, which lies in the mylohyoid sulcus. In the case when the mylohyoid nerve branches off in the mandibular canal, it has its own, separate, ossified canal. Subsequently, after reaching the posterior edge of the mylohoid muscle, the mylohyoid nerve passes on its caudal surface, giving off motor branches to this muscle and to the anterior belly of the digastric muscle $[4,18,59]$. The sensory branches reach the skin around the mental protuberance. This nerve sometimes can join the lingual nerve by a small branch piercing the mylohyoid muscle. It may also take part in the innervation of the last mandibular, molar teeth, giving off numerous branches in the vicinity of the mylohyoid sulcus. It may also participate in the sensory innervation of the canine teeth. In this case it gives off branches going through multiple holes on the lingual side of the mandibular symphysis, which join the incisive nerve (uni- or contralateral). The level at which the mylohyoid nerve branches off the inferior alveolar nerve is variable. It can occur on a distance between 5-23 $\mathrm{mm}$, starting from the point at which the inferior alveolar nerve reaches the mandibular foramen. Thus, the problems that might occur during the anaesthetisation of lower incisor teeth $[4,18,19,25,30]$.

Among the nerves in the immediate vicinity of the mandible that might be significant during standard anaesthesia, is the lingual nerve - the only sensory branch of the anterior trunk. Usually it passes between the heads of the lateral pterygoid muscle or between the lateral and medial pterygoid muscles. Then, it runs with the buccal artery on the lateral surface of the buccal muscle, until it reaches the angle of the mouth. On this rout it divides into terminal branches. They pierce the buccal muscle, but do not innervate him, and supply the buccal mucosa, and partially the gums. They also innervate the skin of the cheek, joining the branches of the facial nerve. The lingual nerve sometimes can be replaced by a branch from the suborbital nerve, or it may branch off directly from the inferior alveolar nerve.

In its initial segment, the buccal nerve runs between the heads of the lateral pterygoid muscle. Next, it goes caudally and anteriorly, and runs at the base of the coronoid process, laterally to the upper jaw tubercle and medially to the temporal muscle ligament [25, 38].

\section{ANTHROPOLOGY}

The mental protuberance of the mandible has undergone multiple changes starting from the Neanderthal to the modern European (in which it is most prominent). Aboriginal Australians have very discreet mental protuberances. Some prehistoric mandibles, as for example the mandible from Mauer (Homo heidelbergensis) has no mental protuberance (Homo amentalis), as in an anthropoid [53]. A prominent mental protuberance is a highly human feature $[16,33,25,53]$.

The mental protuberance develops as a result of the variable intensity of growth of the alveolar part of the mandible and the base of the mandibular corpus. During intrauterine development until the time of birth, the growth of the alveolar part of the mandible is very dynamic $[50,57]$. This part moves anteriorly from the outer margin of the lower edge of the mandible. Between the second and third month after birth, the growth of the alveolar part of the mandible slows down. At the same time the corpus starts to grow faster and thus begins to protrude $[50,57]$. The development of the mental protuberance is partially a symptom of an overall phylogenetic process of cranial formation. Together with the intensification of stimuli, which influenced the growth of the neurocranium (especially anteriorly and superiorly), the intensity of growth of the lower part of the cranium decreased. The viscerocranium has decreased and moved under the neurocranium. These changes caused that the masticatory apparatus moved from its anterior position backwards - under the neurocranium [25].

The widening of the neurocranium, in the process of phylogenesis, resulted in changing of the width of the face - especially the jaw and the palate. The mandible had to adapt to the changing conditions. Gaining the ability to verbally communicate resulted in tongue and mandible enlargement.

The left and right parts of the corpus of the mandible join anteriorly in the midline. As a result of this fusion an arched connection forms. It is less prominent in humans than in other mammals. As a result, severe transverse tensions develop in the bone structure of the mental protuberance $[8,28]$. To reduce these tensions, as well as strengthen the bone structure, the ossicula mentalia are formed. These bones are typical for humans. The small mental bones form in the connective tissue of the mandibular symphysis, shortly before birth. These bones take part in the forming of the characteristic, triangle shaped mental protuberance, which is more prominent in men then in women $[25,28,57]$.

Worth noticing is also the posterior aspect of the mandibular corpus. It is here, where the mental spine is located. It is the place where the genioglossus and the geniohyoid muscles attach $[9,25,57]$. The mental 
spine can be variable in shape and size, even to the point of being non-existent. In its place one sometimes can find the genioglossus fossa $[25,57]$. Such a fossa is a very primitive feature, characteristic for the mandible from Mauer. This mandible belongs to the Homo heidelbergensis species and has been discovered in 1907. It is dated to be 300,000 years old [53]. This species is thought to be the predecessor of the Neanderthals. The genioglossus fossa can sometimes be seen in a child up to 1 year old, or in anthropoids [53, 57].

The coronoid process also undergoes significant changes during the individual development. It is partially formed by the tensions created by the temporal muscle, which attaches to the coronoid process. A wide and low coronoid process is a sign of an intense development of the temporal muscle, while a high and spiky confirms the opposite [8, 25, 38, 39, 63].

\section{HISTORY AND CLINICAL NOTES ON THE SUBJECT OF ANAESTHESIA PERFORMED IN THE VICINITY OF THE MANDIBULAR FORAMEN}

Studies conducted thus far on the subject of the mandibular foramen have concentrated on the race, gender and age-related differences [5, 17, 24, 36, 42, 45]. These differences were both analysed on the panoramic images, as well as on the bone specimens [36, 45, 47].

The first report on the subject of performing cocaine conduction anaesthesia of the inferior alveolar nerve in the region of the mandibular foramen was described by Halsted in 1885 [13]. In 1952 Matas [34] described the history of anaesthesia and its accomplishments associated with nerve blocks over the last 100 years.

Murphy et al. [41] in 1969 described the role of mandibular foramen placement in performing the inferior alveolar nerve block. This team also described accessory mandibular foramina on the mandibular ramus, as well as the variety of innervation of the lower teeth and the course of the inferior alveolar neurovascular bundle.

Barker and Davies [4] in 1972 specified the location of the mandibular foramen, basing on the location of the mandibular lingula. In $47.7 \%$ of the cases the apex of the lingula was about 1-5 mm cranially to the occlusal surface of the lower teeth. Barker and Davies [4] also assessed the correlation between the height of the mandibular ramus and the lingula, and described in detail the structure of the mandible, as well as the pterygo-mandibular space.

Hayward et al. [14] in 1977 noticed that the mandibular foramen is located further from the anterior edge of the mandibular ramus than it is from the posterior edge. They did not find any race, gender and side-related differences in location of the mandibular foramen, as well as in the dimensions of the mandibular rami.

Nicholson [44] in 1985, when assessing a Hindi population, found that the mandibular foramen is located below the occlusal surface of inferior teeth. The author suggests that the reason for inferior alveolar nerve anaesthesia failure is the fact of mandibular foramen variable location in Hindi population.

Hetson et al. [15] in 1988 focused on measuring the distance from the mandibular foramen to the anterior and posterior borders of the mandibular rami, and from the angle of the mandible (Gonion point), using anatomical specimens. They concluded that using the abovementioned parameters provides more accurate measurements, than using isolated landmarks of the bony mandible.

Mwaniki and Hassanali [42] in 1992 found, studying a Kenyan population, that in over $60 \%$ of cases the mandibular foramen is located above the occlusal surface of the inferior teeth. They suggested that when performing inferior alveolar nerve anaesthesia in Kenyans, 1 should administer the injection slightly more cranial than in other populations.

Kaffe et al. [21] in 1994 found a significant correlation between the location of the mandibular foramen in the radiograph and the narrowest anteroposterior dimension of the ramus. They have also noticed that panoramic $X$-ray images made using different machines do not give equal anatomic reconstructions of the mandible.

Jerolimov et al. [17] in 1998 described the location of the mandibular foramen in relation to the temporal crista, and not in relation to the oblique line, as most of the authors have done. They stressed the fact that the location of the mandibular foramen, in relation to the anterior edge of the mandibular ramus, is relatively invariable when compared with the mandibular foramen-posterior edge of the mandibular ramus edge distance. They also noted that the axis of the mandible (distance between the mandibular incision and its base) is individually constant.

Mbajiorgu [36] in 2000 studied the mandibular anatomical specimens of the native population of Zimbabwe. A significant variability has been noticed in the location of the mandibular foramen, and that it rarely lies in the middle of the mandibular ramus.

Keros et al. [24] in 2001 identified the location of the mandibular foramen in relation to the mandibular notch, the angle of the mandible, the anterior and posterior edges of the mandibular rami on panoramic 
$\mathrm{X}$-ray images. These images came from patients that have undergone inferior alveolar nerve anaesthesia - both successful and unsuccessful. The authors have in addition established a correlation between the length of the mandibular axis, the distance between the mandibular foramen and the posterior edge of the mandibular ramus, and also the effect on inferior alveolar nerve anaesthesia. The authors have concluded that the variability in position of the mandibular foramen, among others, may be responsible for an occasional failure of inferior alveolar nerve block.

Oguz and Bozkir [45] in 2002 noted the differences of mandibular ramus dimensions between the left and right sides, and also the fact of the variable location of the mandibular foramen in the sagittal plane (slightly posterior location in relation to the perpendicular axis of the mandible).

Sanchis et al. [54] in 2003 examined radiographically 2012 patients and noted double mandibular canals in $0.35 \%$ of the cases, more common in women.

Das and Suri [7] in 2004 assessed that the mandibular foramen lies slightly above the middle of the mandibular ramus. They noted its irregular build and the possibility of the existence of additional canals. The majority of them are located on the medial surface of the mandibular ramus and usually contain the buccal, mylohyoid or the accessory branch of the inferior alveolar nerve. If they do exist on the later side, they may contain fibres from the facial nerve or the transverse cervical nerve.

Kilarkaje et al. [26] in 2005 described the location of the mandibular foramen in relation to the occlusal plane of the inferior teeth, the condyloid process, the mental symphysis, the mandibular angle, and the anterior edge of the mandibular ramus. The authors concluded that the mandibular foramina show complete symmetry, regardless of age.

Fabian [10] in 2006 assessed the location of the mandibular lingula in relation to the mandibular foramen and the mylohoid sulcus. In most cases the sulcus had its beginning on the medial wall of the mandibular foramen.

Lopez et al. [30] in 2006 stressed the fact that in some cases a bifurcation of the mandibular canal may exist, and that additional foramina may be found on the medial surface of the mandibular ramus. They also described the potential mistakes that can be made when assessing the location of the mandibular lingula. In children, this structure is located on the level of a conventional plane used when performing the inferior alveolar nerve block. In adults, the lingula is located
$1 \mathrm{~cm}$ above the mentioned line. In edentulous patients the lingula is located higher than in patients with teeth. The authors suggest performing routine panoramic $X$-rays to assess the location of the mandibular foramen and canal. They also stress the importance of sound anatomical knowledge when performing anaesthesia in the region of the mandible.

Auluck et al. [2] in 2007 brought to light the necessity of performing routine panoramic $\mathrm{X}$-rays to choose the proper anaesthesia method, especially in the case when double or triple mandibular canals are present.

Galdames et al. [12] in 2008 investigated the role of a tiny canal located in the retromolar triangle, which connects with the mandibular canal. Taking into account the existence of this tiny canal, they have devised a method of delivering anaesthesia through the retromolar triangle. The success rate of anaesthetising the inferior alveolar nerve using this technique is about $27 \%$. The authors recommend using this method in patients with coagulopathies, regardless of the high error rate [12].

Wadhwani et al. [62] in 2008 described a double, right-sided mandibular canal in a live patient. The canal began on the mandibular ramus, with 2 independent foramina. Next, the canals fused with each other on the level of the upper second molar tooth. On the left side, the mandibular canal was triple. The authors recommend taking routine panoramic $\mathrm{X}$-ray images in order to choose the appropriate block method of the inferior alveolar nerve.

Ennes and Medeisros [9] in 2009 assessed the location of the mandibular foramen in relation to the anterior and posterior edge of the mandibular ramus and in the cranial-caudal line. The authors have not found any statistically significant differences between the right and left sides. They did find a high correlation between the angle of the mandibular ramus and the location of the mandibular foramen. However, they do stress the high gender-dependant variability of the location of the foramen. Concluding, the authors propose, that when performing anaesthesia, the needles should be chosen in relation to the width of the mandible ramus. They also warn against using the lower teeth occlusal plane as a reference point, as the mandibular foramen location varies significantly when compared to this point.

Galdames et al. [11] in 2009 assessed the location of the canal of Serres in relation to the mandibular foramen. This canal can be observed in every neonate, and, according to the authors, in $42.6 \%$ of adult cases (more often in women). It is located anteriorly and below or posteriorly and below the mandibular foramen. 
Karamifar et al. [23] in 2009 suggested changing the method of anaesthetising the inferior alveolar nerve, as a result of its possible bifurcation. According to this work, the inferior alveolar nerve runs through 1 canal only in $60 \%$ of cases.

Miloglu et al. [40] in 2009, using panoramic X-ray images, described a double mandibular canal, both on the left and right sides. Both canals have a separate beginning on the mandibular ramus, near the mandibular foramen, and they end in the accessory mental foramen. Taking into account this finding, the classical anaesthesia method may not be sufficient to obtain full anaesthesia in this region.

Bee et al. [5] in 2010 described the lack of significant gender-dependant differences in the location of the mandibular foramen. However, when analysing mandibles from different races (African American and Caucasian), they do note that race influences the location of the mandibular foramen.

Juodzbalys et al. $[17,18]$ in 2010 stressed the importance of the fact that the mandibular canal can bifurcate even if it begins with a single mandibular foramen. The bifurcation can occur both in the transverse and coronal planes. The authors suggest performing a computed tomography of the mandible before teeth implantation to assess the variability of the inferior alveolar nerve.

Prado et al. [47] in 2010 marked the high variability of the mandibular foramen prevalence in the Brasilian population. They did not find any statistical side-related differences in the location of the mandibular foramen, regardless of the state of teeth.

Przystańska and Bruska [48] in 2010 described numerous foramina located on the posterior aspect of the mandible. Immunohistochemistry confirmed that the foramina contained nerve structures and vessels. This suggests the existence of anastomoses between inferior alveolar nerve branches and the accompanying vessels.

Sankar et al. [55] in 2011, when assessing dry dentulous mandibles of both sexes, stated that the most common position of the mental foramen was found below the apex of the second premolar in $73.2 \%$ and between the second premolar and first molar in 19\% of mandibles.

Ashkenazi et al. [1] in 2011 assessed the effect of age on the anteroposterior position of the mandibular foramen and on the size of the gonial angle. Their conclusions were that the mandibular foramen distance from the anterior border of the ramus increased with age, and that the gonial angle decreased with age.
Przystańska and Bruska [49] in 2012 evaluated adult, infantile, and foetal human mandibles for the occurrence of accessory foramina. Accessory mandibular foramina were found to be constant structures of the human mandible. Observations made on children and foetal mandibles showed no significant differences in evaluation of accessory foramina, with the exception of lower occurrence in this group of subjects.

\section{REFERENCES}

1. Ashkenazi M, Taubman L, Gavish A (2011) Age-associated changes of the mandibular foramen position in anteroposterior dimension and of the mandibular angle in dry human mandibles. Anat Rec, 294: 1319-1325.

2. Auluck A, Pai KM, Mupparapu M (2007) Multiple mandibular nerve canals: radiographic observations and clinical relevance. Report of 6 cases. Quintessence Int, 38: 781-787.

3. Balcioglu HA, Kilic C, Varol A, Ozan H, Kocabiyik N, Yildirim MA (2010) Morphometric study of the maxillary artery and lingula in relation to mandibular ramus osteotomies and TMJ surgery. Eur J Dent, 4: 166-170.

4. Barker BC, Davies PL (1972) The applied anatomy of the pterygomandibular space. Br J Oral Surg, 10: 43-55.

5. Bee MT, Rabban M, Sethi H, Tran T, Baker Ch, Forbes B (2010) Variability in the location of the mandibular foramen in African-American and Caucasian population of male and female skulls. Clin Anat, 23: 394-398.

6. Blanton PL, Jeske AH (2003) Avoiding complications in local anesthesia induction: Anatomical considerations. J Am Dent Assoc, 134: 888-893.

7. Das S, Suri R (2004) Anatomico-radiological study of an accessory mandibular foramen on the medial mandibular surface. Folia Morphol, 63: 511-513.

8. Delaire J, Haroun A (2007) Le nouveau concept cortical: la mandibule (deuxieme partie). Bulletin de l'Union National pour I'Interet de I'Orthopedie Dento-Faciale, 32: 16-22.

9. Ennes JP, Medeisros RM (2009) Localization of mandibular foramen and clinical implication. Int J Morphol, 4: 1305-1311.

10. Fabian FM (2006) Observation of the position of the lingula in relation to the mandibular foramen and the mylohyoid groove. Ital J Anat Embryol, 111: 151-158.

11. Galdames ICS, Matamala DAZ, Smith RL (2009) Is the conduct of Serres an anatomical variation in adults? Int J Morphol, 27: 43-47.

12. Galdames ICS, López MGC, Matamala DAZ (2008) Inferior alveolar nerve block anesthesia via the retromolar triangle, an alternative for patients with blood dyscrasias. Med Oral Patol Oral Cir Bucal, 13: 43-47.

13. Halsted WS (1885) Practical comments on the use and abuse of cocaine; suggested by its invariably successful employment in more than thousand minor surgical operations. New York Med J, 42: 294-295.

14. Hayward J, Richardson ER, Malhotra SK (1977) The mandibular foramen: its anteroposterior position. Oral Surg. Oral Med. Oral Pathol, 44: 837-843.

15. Hetson G, Share J, Fommer J, Kronman JH (1988) Statistical evaluation of the position of the mandibular foramen. Oral Surg. Oral Med. Oral Pathol, 65: 32-34.

16. Ichim I, Swain M, Kieser JA (2006) Mandibular Biomechanics and Development of the human. Chin. J Dent Res, 85: 638-642.

17. Jerolimov V, Kolber P, Stanicić T, Bagić I (1998) Assessment of position of foramen mandibulae in recent adult population. Coll Antropol, 22: 169-177. 
18. Juodzbalys G, Wang HL, Sabalys G (2010) Anatomy of Mandibular Vital Structures. Part II: Mandibular Canal and Inferior Alveolar Neurovascular Bundle in Relation with Dental Implantology. J Oral Maxillofac Res, 1: e3.

19. Juodzbalys G., Wang HL, Sabalys G (2010) Anatomy of mandibular vital structures. part i: mandibular canal and inferior alveolar neurovascular bundle in relation with dental implantology. J Oral Maxillofac Res, 1 e2.

20. Kaczkowski H, Porwolik K, Porwolik M, Noga L, Woyton H, Domagala Z, Gworys B (2012) Anatomical analysis of preangular mandibular notch in humans. Folia Morphol, 71: 100-104.

21. Kaffe I, Ardekian L, Gelerenter I, Taicher S (1994) Location of the mandibular foramen in panoramic radiographs. Oral Surg Oral Med Oral Pathol, 78: 662-669.

22. Kalinowski P, Różyło-Kalinowska I (2011) Panoramic radiomorphometric parameters in Polish patients. Folia Morphol, 70: 168-174.

23. Karamifar K, Shahidi S, Tondari A (2009) Bilateral bifid mandibular canal: report of two cases. Indian J Dent Res, 20: 235-237.

24. Keros J, Kobler P, Baucić I, Cabov T (2001) Foramen mandibulae as an indicator of successful conduction anaesthesia. Coll Antropol, 25: 327-331.

25. Kharoshah MAA, Almadani O, Ghaleb SS, Zaki MK, Fattah YAA (2010) Sexual dimorphism of the mandible in a modern Egyptian population. J Forensic Legal Med, 17: 213-215.

26. Kilarkaje N, Nayak SR, Narayan P, Prabhu LV (2005) The location of the mandibular foramen maintains absolute bilateral symmetry in mandibles of different age-groups. Hong Kong Dent J, 2: 35-37.

27. Lazarov N, Usunoff K (2003) Descending projections from the trigeminal ganglion and mesencephalic trigeminal nucleus. Trakia J Scienc, 1: 5-14.

28. Lee SK, Kim YS, Oh HS, Yang KH, Kim EC, Chi JG (2001) Prenatal development of the human mandible. Anat Rec, 263: 314-325.

29. Lima AN, Cespedes IC (2009) Fatores que levam ao sucesso da anestsia Pterigomandibular. Revista Odonto, 17: 70-78.

30. López AB, Diago MP (2006) Failure of locoregional anaesthesia in dental practice. Review of the literature. Oral Patol Oral Cir Bucal, 11: 510-513.

31. Madrid C, Reynes P (1989) The fasciae of the pterygomandibular space. Acta Anat, 136: 55-60.

32. Malamed SF (1981) The Gow-Gates mandibular block. Evaluation after 4,275 cases. Oral Surg Oral Med Oral Pathol, 51: 463-467.

33. Manikandhan R, Mathew PC, Naveenkumar J, Anantanarayanan P (2010) A rare variation in the course of the inferior alveolar nerve. Int J Oral Maxillofac Surg, 39: 185-187.

34. Matas R (1952) The story of the Discovery of dental anesthesia by nerve bloking: achievements of William Stewart Halsted. Surgery, 32: $530-537$

35. Mbajiorgu FE, Zivanovic S, Asala SA, Mawera G (1996) A pilot study of the mandibular angle in black Zimbabweans. Cent Afr J Med, 42: 285-287.

36. Mbajiorgu FE (2000) A study of the position of the mandibular foramen in adult black Zimbabwean mandibles. Central Afr J Med, 46: 184-190.

37. Meechan JG (2002) Supplementary routes to local anaesthesia Intern Endodont J, 35: 885-896.

38. Mérida-Velasco JR, Rodríguez-Vázquez JF, de la Cuadra C, Mérida-Velasco JA, Jiménez-Collado J (2001) The course of the buccal nerve: relationships with the tempo-ralis muscle during the prenatal period. J Anat, 198: 423-429.

39. Merrot O, Vacher C, Merrot S, Godlewski G, Frigard B, Goudot P (2005) Changes in the edentate mandible in the eldery. Surg Radiol Anat, 27: 265-270.

40. Miloglu O, Yilmaz AB, Caglayan F (2009) Bilateral bifid mandibular canal: a case report. Med Oral Patol Oral Cir Bucal, 14: 244-246.

41. Murphy TR, Grundy EM (1969) The inferior alveolar neurovascular bundle at the mandibular foramen. Dent Pract, 20: 41-48.
42. Mwaniki DL, Hassanali J (1992) The position of mandibular and mental foramina in Kenyan African mandibles. East Afr Med J, 69: 210-213.

43. Naitoh M, Hiraiwa Y, Aimiya H, Ariji E (2009) Observation of bifid mandibular canal using cone-beam computerized tomography. Int J Oral Maxillofac Implants, 24: 155-159.

44. Nicholson ML (1985) A study of the position of the mandibular foramen in the adult human mandible. Anat Rec, 212: 110-112.

45. Oguz O, Bozkir MG (2002) Evaluation of location of mandibular and mental foramina in dry, young, adult human male, dentulous mandibles. West Indian Med J, 51: 14-16.

46. Orliaguet T, De'chelotte P, Scheye T, Vanneuville G (1993) The relationship between Meckel's cartilage and the development of the human fetal mandible. Surg Radiol Anat, 15: 113-118.

47. Prado FB, Groppo FC, Volpato MC, Caria PHF (2010) Morphologica changes in the position of the mandibular foramen in dentate and edentate Brazilian subjects. Clin. Anat, 23: 394-398.

48. Przystańska A, Bruska M (2010) Accessory mandibular foramina: histological and immunohistochemical studies of their contents. Arch Oral Biol, 55: 77-80.

49. Przystańska A, Bruska M (2012) Anatomical classification of accessory foramina in human mandibles of adults, infants, and fetuses. Anat Sci Int, 87: 141-149.

50. Radlanski RJ, Renz H, Klarkowski MC (2003) Prenatal development of the human mandible. 3D reconstructions, morphometry and bone remodelling pattern, sizes 12-117 mm CRL. Anat Embryol, 207: 221-232.

51. Roda RS, Blanton PL (1994) The anatomy of local anaesthesia. Quint Intern, 25: 27-38.

52. Rodriguez-Vazquez JF, Verdugo-Lopez S, Murakami G (2011) Venous drainage from the developing human base of mandible including Meckel's cartilage: the so-called Serres' vein revisited. Surg Radiol Anat, 33: 575-581.

53. Rosas A, Bermudez de Castro JM (1998) The Mauer mandible and the evolutionary significance of Homo heidelbergensis. Geobios, 31: 687-697.

54. Sanchis JM, Penarrocha M, Soler F (2003) Bifid mandibular canal. J Oral Maxillofac Surg, 61: 422-424.

55. Sankar DK, Bhanu SP, Susan PJ (2011) Morphometrical and morphological study of mental foramen in dry dentulous mandibles of South Andhra population of India. Indian J Dent Res, 22: 542-546.

56. Sawyer DR, Kiely ML (1991) Retromolar foramen: a mandibular variant important to dentistry. Ann Dent, 50: 16-18.

57. Schwartz JH, Tattersall I (2000) The human chin revisited: what is it and who has it? J Hum Evol, 38: 367-409.

58. Siéssere S, Hallak Regalo SC, Semprini M, Honorato De Oliveira R, Vitti M, Mizusaki lyomasa M, Mardegan Issa JP, De Sousa LG (2009) Anatomical variations of the mandibular nerve and its branches correlated to clinical situations. Minerva Stomatol, 58: 209-215.

59. Skrzat J, Mróz I, Walocha J, Zawiliński J, Jaworek JK (2007) Bilateral ossification of the stylohyoid ligament. Folia Morphol, 66: 203-206.

60. Skrzat J, Walocha J, Srodek R, Nizankowska A (2006) An atypical position of the foramen ovale. Folia Morphol, 65: 396-399.

61. Skrzat J, Walocha J, Srodek R (2005) An anatomical study of the pterygoalar bar and the pterygoalar foramen. Folia Morphol, 64: 92-96.

62. Wadhwani P, Mathur RM, Kohli M, Sahu R (2008) Mandibular canal variant: a case re-port. J Oral Pathol Med, 37: 122-124.

63. Żurowski R, Gosek M, Aleksandrowicz R (1976) Dimensions and geometry of the temporomandibular joint and masseter muscles. Pol Med Sci Hist Bull, 15: 291-295. 